\title{
Localization of the Binding Site of Tissue-Type Plasminogen Activator to Fibrin
}

\author{
Akitada Ichinose, Koji Takio, and Kazuo Fujikawa \\ Department of Biochemistry, University of Washington; The Howard Hughes Medical Institute, Seattle, Washington 98195
}

\begin{abstract}
Functionally active $A$ and $B$ chains were separated from a twochain form of recombinant tissue-type plasminogen activator after mild reduction and alkylation. The $A$ chain was found to be responsible for the binding to lysine-Sepharose or fibrin and the B chain contained the catalytic activity of tissue-type plasminogen activator. An extensive reduction of two-chain tissue-type plasminogen activator, however, destroyed both the binding and catalytic activities. A thermolytic fragment, Fr. 1, of tissue-type plasminogen activator that contained a growth factor and two kringle segments retained its lysine binding activity. Additional thermolytic cleavages in the kringle- 2 segment of Fr. 1 caused a total loss of the binding activity. These results indicated that the binding site of tissue-type plasminogen activator to fibrin was located in the kringle- 2 segment.
\end{abstract}

\section{Introduction}

Plasmin is the sole enzyme responsible for the resolution of thrombi in mammals. Plasmin circulates in blood in its zymogen form, plasminogen. It is converted to plasmin by tissue-type plasminogen activator (tPA). ${ }^{1}$ tPA is synthesized in endothelial cells $(1,2)$ and released into plasma by various stimuli $(3)$. A trace amount of tPA is found in blood $(3,4)$. The fibrinolytic activity is, however, detectable in plasma only after fibrin clots are formed $(5,6)$. This phenomenon is in accord with the finding that the enzyme activity of IPA is greatly enhanced, when it hydrolyzes plasminogen in the presence of fibrin $(7,8)$.

The enhancement of fibrinolytic activity of tPA is apparently due to the conformational changes of tPA within a complex with plasminogen and fibrin (8). Both plasminogen and tPA have binding affinity to fibrin $(9,10)$. The binding property of plasminogen to fibrin has been characterized. Lysine or $\epsilon$-amino caproic acid (EACA) binds to plasminogen in a region that contains the first three kringles (kringle 1-3) and competitively inhibits the binding of plasminogen to fibrin (10-12). Therefore, fibrin and these amino acids presumably share a common binding site on the plasminogen molecule (13). Lerch et al. isolated

A preliminary report of this work was presented at the meeting of the Xth International Congress on Thrombosis and Hemostasis, San Diego, CA, and published in abstract form. (1985. Thromb. Hemostasis. 54:60 Abstr.)

Address reprint requests to Dr. Fujikawa, Department of Biochemistry, University of Washington, Seattle, WA 98195.

Received for publication 12 December 1985.

1. Abbreviations used in this paper: EACA, $\epsilon$-amino caproic acid; IAA, iodoacetoamide; TB, $50 \mathrm{mM}$ Tris- $\mathrm{HCl}$ buffer, $\mathrm{pH}$ 7.5; tPA, tissue-type plasminogen activator.

J. Clin. Invest.

(C) The American Society for Clinical Investigation, Inc.

0021-9738/86/07/0163/07 \$1.00

Volume 78, July 1986, 163-169 the kringle-1 segment from plasminogen and demonstrated that this segment had a high binding affinity with EACA (14). Recently, two Arg residues in kringle-1 of plasminogen have been found to be involved in the binding to fibrin (15). tPA has been shown to bind to fibrin-Sepharose and to be eluted by a buffer containing lysine (16). This chromatographic behavior indicates that tPA also contains a common binding site to lysine and fibrin. The location of the binding site of tPA to fibrin, however, has not been studied.

tPA is synthesized as a single-chain precursor (17) and is proteolytically activated in vitro into a two-chain form by plas$\min (17,18)$, tissue kallikrein and activated Factor X (19). Twochain tPA consists of an A and a B chain that are connected by an interchain disulfide bond. The complete amino acid and cDNA sequences of tPA have been determined (20-22) and revealed that $\mathrm{PA}$ contained in the A chain a region that comprised two consecutive kringle segments. This region is structurally analogous to the kringle 1-3 fragment in plasminogen (23) and could be a binding site of tPA to fibrin. In addition to the kringles, the A chain has one type I segment that was found in fibronectin and one growth factor segment at the amino terminal portion, while the structure of the B chain is typical of serine proteases.

In this communication, we report that the binding site of tPA to lysine-Sepharose or fibrin is located in its kringle-2 segment.

\section{Methods}

A two-chain form of recombinant tPA was a gift from Dr. Gordon Vehar of Genentech, South San Francisco, CA. Thermolysin was purchased from Calbiochem, La Jolla, CA. The peptide substrate (S-2322) was a gift from Kabi Peptide Research, Molndal, Sweden. Lysine-Sepharose was prepared according to the published method (24).

tPA was radiolabeled with ${ }^{125} \mathrm{I}-\mathrm{Na}$ (Amersham Corp., Arlington Heights, IL) using Enzymobeads (Bio-Rad Laboratories, Richmond, CA). To remove inactivated molecular species of tPA that were formed during iodination, ${ }^{125}$ I-tPA was adsorbed on a lysine-Sepharose column equilibrated with Tris-buffered (TB)-Tween containing $0.3 \mathrm{M} \mathrm{NaCl}$ and eluted with TB-Tween containing $1 \mathrm{M} \mathrm{EACA}$ and $0.3 \mathrm{M} \mathrm{NaCl}$. The tPA fraction was then applied to a Sephadex G-15 column with TB-Tween containing $0.3 \mathrm{M} \mathrm{NaCl}$ to remove EACA. Recovery of ${ }^{125} \mathrm{I}$-tPA after these two columns was $\sim 60 \%$.

Sodium dodecyl sulfate (SDS)-slab gel electrophoresis was performed in $12 \%$ polyacrylamide as described by Laemmli. Protein bands were visualized by silver staining.

In order to determine the optimum concentration of reducing agent for the separation of the active $A$ and $B$ chains, $5 \mathrm{ng}$ of two-chain ${ }^{125} \mathrm{I}$ tPA (total 9,000 cpm) were incubated at room temperature for $2 \mathrm{~h}$ with several concentrations of dithiothreitol (DTT). Iodoacetoamide (IAA) was then added to the reactions at $5 \mathrm{mM}$ and incubated for $30 \mathrm{~min}$ in the dark. The sample was applied to a lysine-Sepharose column $\mathbf{( 0 . 7}$ $\times 3.0 \mathrm{~cm}$ ). After washing the column with TB-Tween containing $0.3 \mathrm{M}$ $\mathrm{NaCl}$, adsorbed tPA was eluted with TB-Tween containing 1 M EACA and $0.3 \mathrm{M} \mathrm{NaCl}$ as described above. The amount of tPA bound to lysineSepharose was expressed as a percentage of the radioactivity in the EACA eluate. 
For the separation of $S$-carboxyamidomethyl A and B chains, twochain tPA $(200 \mu \mathrm{g})$ in $0.6 \mathrm{ml}$ TB-Tween containing $0.5 \mathrm{mM} \mathrm{NaCl}, 5$ $\mathrm{mM}$ benzamidine and $2.5 \mathrm{mM}$ EDTA was incubated with $33 \mu \mathrm{l}$ of 100 $\mathrm{mM}$ DTT (final $5 \mathrm{mM}$ ) for $2 \mathrm{~h}$. Then, $33 \mu \mathrm{l}$ of $100 \mathrm{mM}$ IAA (final 5 $\mathrm{mM}$ ) was added and incubated for $30 \mathrm{~min}$ in the dark. After the mixture was diluted threefold with TB-Tween, it was dialyzed against TB-Tween containing $0.3 \mathrm{M} \mathrm{NaCl}$. The sample was applied to a lysine-Sepharose column $(0.7 \times 20 \mathrm{~cm})$ equilibrated with TB-Tween containing $0.3 \mathrm{M}$ $\mathrm{NaCl}$. After washing the column with TB-Tween containing $0.3 \mathrm{M} \mathrm{NaCl}$, protein was eluted with TB-Tween containing $1 \mathrm{M}$ EACA and $0.3 \mathrm{M}$ $\mathrm{NaCl}$. The unadsorbed and eluted fractions were pooled separately and dialyzed against TB-Tween containing $0.3 \mathrm{M} \mathrm{NaCl}$. Amidolytic activities of the dialyzed fractions were assayed as previously described (19) using a synthetic substrate, Val-Gly-Arg-p-nitroanilide (S-2322). This substrate is fairly specific and has a high sensitivity to tPA (25).

Separation of $S$-carboxyamidomethyl A and B chain was also performed using a reverse-phase column (Ultrapore C3, Altex Scientific, Inc., Berkeley, CA, $4.6 \times 75 \mathrm{~mm}$ ) connected to a Waters high performance liquid chromatography (HPLC) system (Waters Associates, Millipore Corp., Milford, MA). The gradient consisted of $0.1 \%$ trifluoroacetic acid (solvent $\mathrm{A}$ ) as mobile phase and $0.08 \%$ trifluoroacetic acid in $80 \%$ acetonitrile (solvent B) as mobile phase modifier. The column was run at a flow rate of $1.5 \mathrm{ml} / \mathrm{min}$. The effluent was monitored by absorbance at $214 \mathrm{~nm}$.

Digestion of two-chain tPA with thermolysin was carried out in TBTween containing $0.5 \mathrm{M} \mathrm{NaCl}$ at $37^{\circ} \mathrm{C}$ with an enzyme/substrate weight ratio of $1 / 30$. Separation of peptide fragments was performed by reversephase HPLC as described above.

Sequence analysis of the peptide fragments was performed by a model 470A Protein Sequenator (Biosystems, Foster City, CA). Phenylthiohydantoin (PTH)-amino acids were analyzed by two complementary reverse-phase HPLC systems $(26,27)$.

\section{Results}

Separation of the functionally active $A$ and $B$ chains of $t P A$. Twochain tPA is composed of a doublet of an A chain with molecular masses 35 and $32 \mathrm{kD}$, and a B chain with a molecular mass 32 $\mathrm{kD}(18,28)$. These two chains are linked by one interchain disulfide bond (21). To localize the binding region of tPA to fibrin or the antifibrinolytic amino acids, lysine and EACA, separation of active $A$ and $B$ chains of TPA was attempted with affinity chromatography on lysine-Sepharose column after mild reduction of two-chain tPA. For this experiment, the conditions of van der Graaf et al. (29), which were developed for the separation of the functionally active heavy and light chains of plasma kallikrein, applied with some modifications.

Two-chain ${ }^{125} \mathrm{I}$-tPA was incubated with several concentrations of DTT and the degree of reduction was determined by applying an aliquot of the samples to the lysine-Sepharose column. All of the ${ }^{125}$ I-tPA adsorbed to the column if the reducing reagent was not present in the reaction. The radioactivity in the nonadsorbed fraction increased in parallel with the increasing concentration of DTT. $43 \%$ of radioactivity passed through the column in the presence of $2.5 \mathrm{mM}$ DTT and $62 \%$ of ${ }^{125} \mathrm{I}$-tPA passed through the column at $5 \mathrm{mM}$ DTT. More than $98 \%$ of tPA was found in the pass-through fraction at $100 \mathrm{mM}$ DTT. These data suggested that the lowest concentration of DTT required for the complete reduction of the interchain disulfide bond of two-chain tPA was around $5 \mathrm{mM}$.

A larger amount of two-chain tPA $(200 \mu \mathrm{g})$ was reduced and alkylated as described in Methods. The sample was then applied to the lysine-Sepharose column. Adsorbed protein was eluted with the buffer containing 1 M EACA. Based on the absorbance at $280 \mathrm{~nm}, \sim 70 \%$ of the protein passed through the column and the remaining $30 \%$ was recovered in the eluate (Fig. 1). Both protein fractions were concentrated and subjected to SDS-polyacrylamide slab gel electrophoresis. Protein from the unadsorbed fraction gave a band of an approximate molecular mass of 32 $\mathrm{kD}$ and the protein eluted with $1 \mathrm{M}$ EACA showed a characteristic doublet band corresponding to molecular mass of 35 and $32 \mathrm{kD}$, indicating that the unadsorbed fraction contained the $\mathrm{B}$ chain and the eluate contained the $A$ chain.

The separated A and B chains of tPA were also analyzed by reverse-phase HPLC to establish their homogeneity. Two-chain tPA eluted in a single peak from an Altex C3 column at $21 \mathrm{~min}$ (Fig. 2,I), while the reduced and alkylated tPA separated into two distinct peaks eluted at 19 and $22 \mathrm{~min}$, respectively (Fig. 2, II). The materials in the unadsorbed fraction (B chain) and the EACA eluate (A chain) from the lysine-Sepharose column emerged as single symmetrical peaks at exactly the same positions as those obtained with reduced and alkylated two-chain tPA (Fig. 2, III and $I V$ ), showing that the alkylated A and B chains were homogeneous.

Table I shows the amidolytic activity before and after the separation of the A and B chains by the lysine-Sepharose column. tPA was slightly denatured after reduction with $5 \mathrm{mM}$ DTT resulting in a $72 \%$ recovery of the amidolytic activity. $65 \%$ of the original activity was recovered in the unadsorbed fraction (B chain). The specific activity of the separated B chain was $15 \%$ lower than intact two-chain tPA. A trace of the enzyme activity (3\%) was found in the eluate (A chain).

These results clarified that the binding site of tPA to the antifibrinolytic amino acids or fibrin was located in the A chain and the $\mathrm{B}$ chain contained the catalytic activity.

Localization of lysine binding site of $P$ PA. Limited proteolysis of two-chain tPA with several enzymes (trypsin, chymotrypsin, tissue kallikrein, plasmin, elastase, Staphylococcus aureus V8 protease, lysyl-endopeptidase and thermolysin) was conducted to localize the binding site in the A chain of tPA. Of these enzymes, digestion with thermolysin gave the most promising

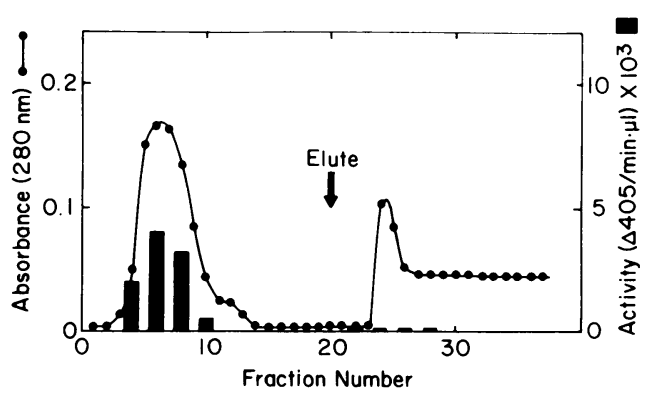

Figure 1. Separation of the $S$-carboxyamidomethyl A and B chains of two-chain tPA by the lysine-Sepharose column. $200 \mu \mathrm{g}$ of two-chain tPA were reduced with $5 \mathrm{mM}$ DTT and alkylated with $5 \mathrm{mM}$ IAA as described in Methods. After the sample was dialyzed against TBTween containing $0.5 \mathrm{M} \mathrm{NaCl}$, it was applied to a lysine-Sepharose column $(0.7 \times 20 \mathrm{~cm})$ and the column was washed with the same buffer. Adsorbed protein was eluted with TB-Tween containing $1 \mathrm{M}$ EACA and $0.3 \mathrm{M} \mathrm{NaCl}$. Fractions of $0.5 \mathrm{ml} /$ tube were collected. The amidolytic activity in each fraction was assayed using Val-Gly-Arg-pnitroanilide (S-2322). Protein concentration was determined by absorbance at $280 \mathrm{~nm}$. 


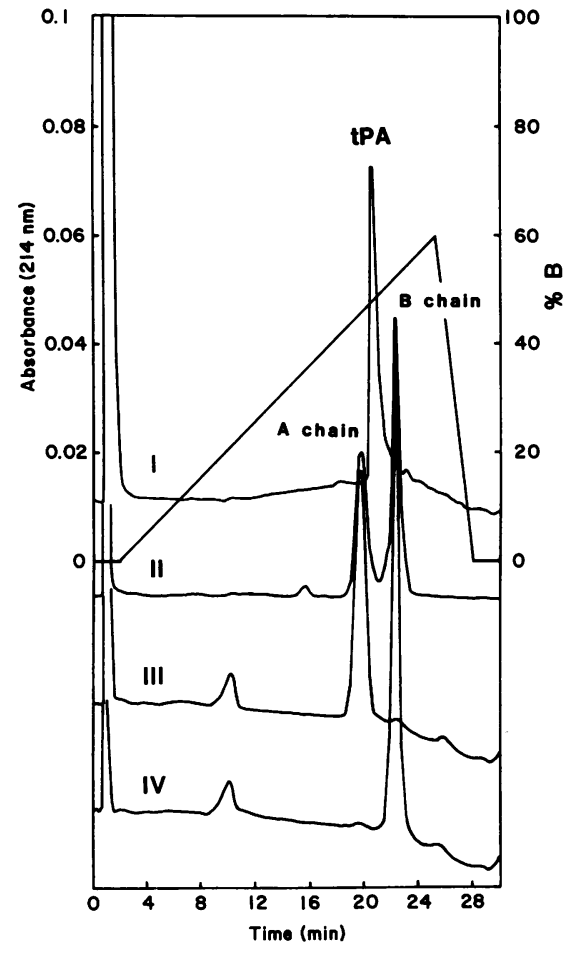

Figure 2. HPLC separation of the A and B chains of tPA. The materials were injected into an Altex Ultrapore $C 3$ column $(4.6 \times 75 \mathrm{~mm})$ connected to a Waters HPLC system. The gradient was composed of $0.1 \%$ trifluoroacetic acid (solvent $\mathrm{A}$ ) and $0.08 \%$ trifluoroacetic acid in $80 \%$ acetonitrile (solvent $B$ ) and a flow rate of $1.5 \mathrm{ml} / \mathrm{min}$ was employed. Intact two-chain tPA (I); reduced and alkylated two-chain tPA with $5 \mathrm{mM}$ DTT and $5 \mathrm{mM}$ IAA (II); the eluate (III) and the unadsorbed fraction $(I V)$ of reduced and alkylated tPA from the lysine-Sepharose column. Percentage of the solvent $B$ in the gradient is shown on the right ordinate.

fragmentation. Two-chain tPA (300 $\mu \mathrm{g}, 4 \mathrm{nmol})$ was digested with thermolysin $(10 \mu \mathrm{g})$. During the digestion, small aliquots were taken at various times and analyzed by reverse-phase HPLC using the Altex column. At zero time, the starting two-chain tPA eluted as a single peak from the column (Fig. $3 \mathrm{~A}, I$ ). At 20 h, $50 \%$ of tPA was degraded and produced a major fragment, Fr. 1, along with several minor fragments (Fig. $3 A, I I$ ). Further digestion for $\mathbf{4 4} \mathrm{h}$ generated another major fragment, Fr. 2 (Fig. $3 A, I I I)$. The Fr. 2 peak increased at $68 \mathrm{~h}$ with a concomitant decrease of the Fr. 1 peak (Fig. $3 A, I V$ and Fig. $3 B, V$ ), indicating that Fr. 1 was a precursor of Fr. 2 . After $68 \mathrm{~h}$, the remaining digest was applied to the lysine-Sepharose column. The unadsorbed and EACA eluate fractions were obtained as described in Methods and each was analyzed by HPLC using the Altex column. Only Fr. 1 was found in the eluate (Fig. $3 B, V I$ ) and all other peaks, including Fr. 2, that were present in the 68-h digest were found in the unadsorbed fractions (Fig. $3 B, V I I$ ). These results indicated that Fr. 1 was the smallest thermolytic fragment that could retain the binding activity to the lysineSepharose column.

The two isolated major fragments, Fr. 1 and Fr 2, were analyzed for their amino-terminal sequence. The amounts of the materials that were used for sequence analysis contained approximately one-third of the original digest $(1.5 \mathrm{nmol})$. Sequence analysis of Fr. 1 continued to the cycle 15. Major PTH-amino
Table I. Amidolytic Activities of the Isolated $S$-Carboxyamidomethyl $A$ and $B$ Chains

\begin{tabular}{llllll}
\hline Preparations & Volume & $\begin{array}{l}\text { Protein } \\
\text { A280 }\end{array}$ & Activity & $\begin{array}{l}\text { Specific } \\
\text { activity }\end{array}$ & Yield \\
\hline & $m l$ & & $\begin{array}{c}\Delta A 405 / m i n \\
\text { in } 10 \mu l\end{array}$ & $\begin{array}{l}\text { activity } \\
\text { A280 }\end{array}$ & $\%$ \\
$\begin{array}{c}\text { Two-chain tPA } \\
\text { Reduced and alkylated } \\
\quad \text { tPA }\end{array}$ & 0.6 & 0.88 & 0.50 & 0.57 & 100 \\
$\begin{array}{c}\text { Fractions from lysine- } \\
\quad \text { Sepharose* }\end{array}$ & 1.8 & 0.28 & 0.12 & 0.43 & 72 \\
$\begin{array}{c}\text { Unadsorbed } \\
\text { (B chain) } \\
\text { Adsorbed and eluted } \\
\text { (A chain) }\end{array}$ & 3.0 & 0.14 & 0.07 & 0.49 & 65 \\
\hline
\end{tabular}

All samples were dialyzed against TB-Tween containing $0.3 \mathrm{M} \mathrm{NaCl}$ before assay.

Amidolytic activities were assayed using Val-Gly-Arg-p-nitroanilide (S-2322) as previously described (19).

* The fractions 4-9 and 23-28 from the lysine-Sepharose column

(Fig. 1) were separately pooled.

acids found in each cycle are shown in Table II and the yields of the PTH-amino acids are presented in the legend of the table. Without alkylation of the samples, half cystinyl residues were not detectable and the presence of half cystinyl residues in the fragments were assigned by the published sequence (21). By comparing with the established tPA sequence, three sequences were found to satisfy the analysis of Fr. 1: the first started with $\mathrm{Val} 48$ to Thr 61 in the growth factor segment, the second from Phe 71 to Glu 85 also in the growth factor segment, the third was a heptapeptide, Val 394 to Asp 400 from the B chain. The structure of Fr. 1 thus was found to consist of a growth factor segment that was cleaved between the Asp 70 and Phe 71 bond, and two intact kringles followed by a part of the connecting region to which a heptapeptide of the B chain was connected by a disulfide bond (Fig. 4, left).

The molecular mass of Fr. 1 was found to be $\sim 29 \mathrm{kD}$ in the absence of reducing agent (Fig. 5, B). This value is in good agreement with the molecular mass calculated from the composition of the structure shown in Fig. 4. This structure contains 235 amino acid residues and two Asn-linked carbohydrate chains at 107 and 184. In the presence of reducing agent, the molecular mass of Fr. 1 was found to be $\sim 26 \mathrm{kD}$ (Fig. $5, E$ ). The decrease of the molecular weight of Fr. 1 under reducing condition is accounted for by the removal of a half of the growth factor and a heptapeptide. At present, it is not known whether all of the residues Gln 63-Asp 70 in the growth factor segment and the carboxyl-terminal 11 residues Gly 265-Arg 275 that follows the kringle-2 segment are contained in Fr. 1 or not.

Similarly, sequence of Fr. 2 was analyzed for 10 cycles and four major sequences were found in this fragment (Table II). The first three sequences were the same as found in Fr. 1. The fourth sequence was found to be located at Leu 226 to Pro 235, indicating that a cleavage(s) occurred between Gly 225 and Leu 226 in the kringle-2 segment during the conversion of Fr. 1 to Fr. 2 (Fig. 4, right). There was no indication of peptide bond 

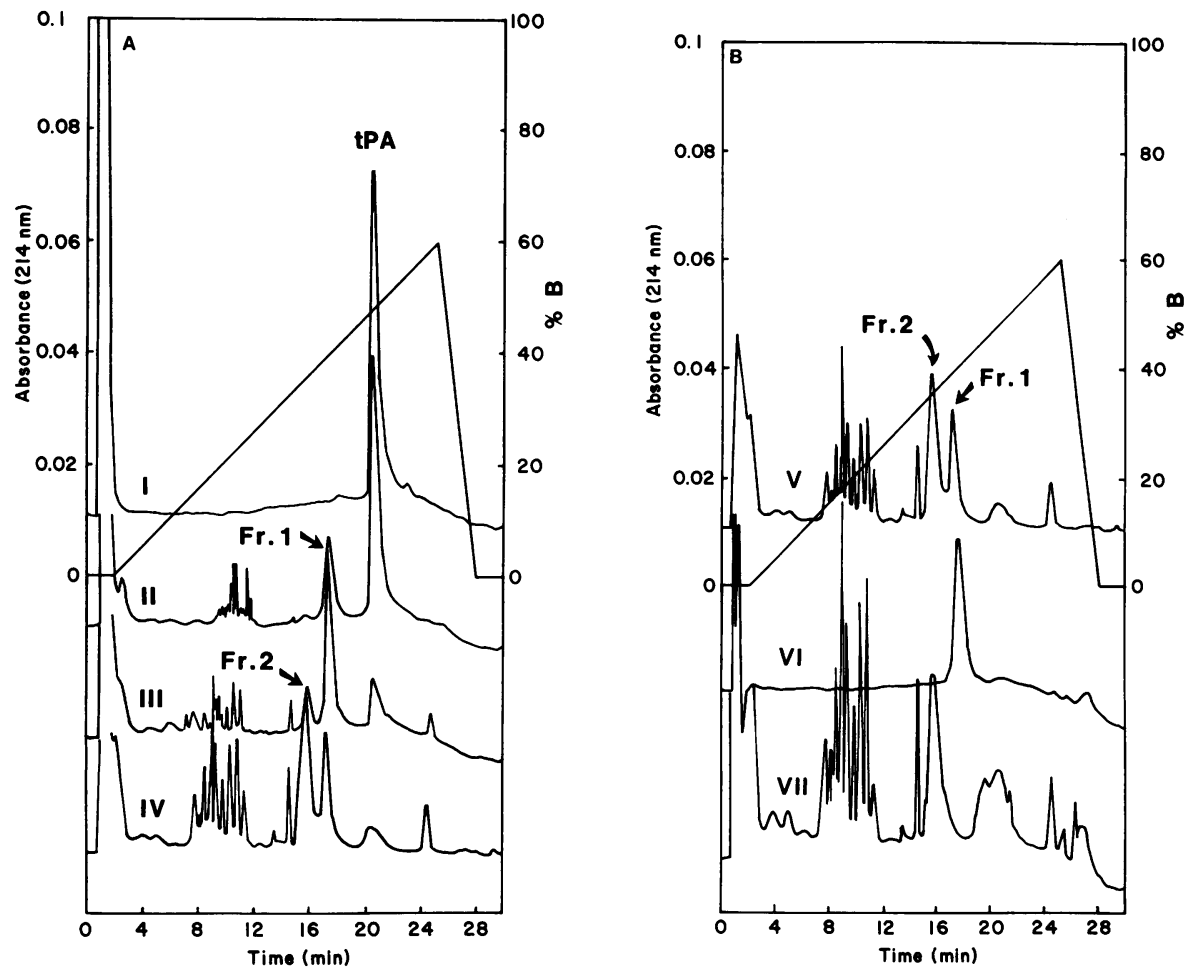

Figure 3. Analysis and isolation of the thermolytic fragments of two-chain tPA. 4 nmol $(300 \mu \mathrm{g})$ of two-chain tPA were digested with $10 \mu \mathrm{g}$ of thermolysin at $37^{\circ} \mathrm{C}$. At time intervals, a portion of the digest was injected into the Altex reverse-phase column; $0(I), 20(I I), 44(I I I)$, and $68 \mathrm{~h}$ $(I V$ and $V$ ). After $68 \mathrm{~h}$, the remaining sample was applied to the lysine-Sepharose column. The unadsorbed fraction and the eluate with 1 M EACA were prepared as described in Methods and applied to the Altex column; the eluate $(V I)$ and unadsorbed fractions $(V I I)$. Fractions of each peak were collected for sequence analysis.

cleavage in the kringle- 1 segment by the sequence analysis of Fr. 1 and Fr. 2.

With a single additional cleavage at Gly 225 and Leu 226, Fr. 2 should have the same molecular mass as Fr. 1. Fr. 2 was determined to be $26 \mathrm{kD}$ in the nonreduced gel (Fig. 5, C). Con-

Table II. Amino Acid Sequences of the Thermolytic Fragments, Fr. 1 and Fr. 2, Derived from two-chain $t P A$

Fr. 1 1 5 10 15

1 (48-61) Val-Lys-Ser-Cys-Ser-Glu-Pro-Arg-Cys-Phe-Asn-Gly-Gly-Thr-Cys2 (71-85) Phe-Val-Cys-Gln-Cys-Pro-Glu-Gly-Phe-Ala-Gly-Lys-Cys-Cys-Glu3 (394-400) Val-Cys-Leu-Pro-Pro-Ala-Asp

Fr. 2

$1(47-56) \quad \begin{aligned} & 1 \\ & \text { Val-Lys-Ser-Cys-Ser-Glu-Pro-Arg-Cys-Phe- }\end{aligned}$

2 (71-80) Phe-Val-Cys-GIn-Cys-Pro-Glu-Gly-Phe-Ala-

3 (394-400) Val-Cys-Leu-Pro-Pro-Ala-Asp

4 (226-235) Leu-Gly-Lys-His-Asn-Tyr-Cys-Arg-Asn-Pro-

The quantities (nmol) of PTH-amino acids recovered in each cycle were as follows: in Fr. 1, $1 \mathrm{Val}(0.5)$, $\operatorname{Phe}(0.3) ; 2 \operatorname{Lys}(0.3), \operatorname{Val}(0.3) ; 3 \operatorname{Ser}(0.06)$; Leu(0.2); 4 $\operatorname{Gln}(0.2)$, Pro(0.2); 5 Ser(0.07), Pro(0.2); 6 Glu(0.1), Pro(0.1), Ala(0.1); 7

Pro(0.1), Glu(0.3), Asp(0.04), 8 Arg(0.1), Gly(0.2); 9 Phe(0.1); 10 Phe(0.1), Ala(0.2); 11 Asn(0.07), Gly(0.1); 12 Gly(0.1), Lys(0.1); 13 Gly(0.1); 14 Thr(0.03); $15 \mathrm{Glu}(0.06)$.

In Fr. 2, $1 \mathrm{Val}(1.5)$, Phe(0.8), Leu(1.2); $2 \mathrm{Lys}(0.3)$, $\operatorname{Val}(0.7), \operatorname{Gly}(0.5) ; 3 \operatorname{Ser}(0.2)$, Leu(0.6), Lys(0.3); $4 \mathrm{GIn}(0.3)$, $\operatorname{Pro}(0.5)$, His(0.1); $5 \operatorname{Ser}(0.1)$, $\operatorname{Pro}(0.5)$, Asn(0.2); 6 Glu(0.2), Pro(0.4), Ala(0.4), Tyr(0.2); 7 Pro(0.3), Glu(0.3), Asp(0.1); 8 Arg(0.2), Gly(0.3); 9 Phe(0.3), Asn(0.1);

10 Phe(0.3), Ala(0.4), Pro(0.3).

The Cys residues were assigned from the published sequence of tPA (21).

The sequences that were marked by - at their ends continue further and the sequences that were not marked terminate as they are shown. sidering an apparent 3-kD smaller molecular mass of this fragment than Fr. 1, a peptide(s) was likely removed by a second cleavage(s) in kringle-2. The peptide bonds at Cys-Leu (201202), Ile-Leu (208-209), Leu-Ile (209-210), Lys-Val (212-213) and Ala-Leu (223-224) are presumed for the second cleavage from the specificity of thermolysin. Any one or more of these cleavage(s) removes a peptide(s) from the kringle- 2 in Fr. 1 and results in the generation of Fr. 2. Given that the bond between Cys 201 and Leu 202 is cleaved, Fr. 2 separates into five fragments by reduction: Val 48 to Asp 70, Phe 71 to Cys 201, Leu 202 to Gly 225, Leu 226 to Arg 275, and Val 394 to Asn 400. The reduced sample of Fr. 2 showed one single band on SDS gel with a molecular mass of $\sim 19 \mathrm{kD}$ (Fig. 5, F). This molecular mass agrees with that calculated from the composition of the largest fragment, Phe 71 to Cys 201. This fragment contains 140 amino acid residues and one carbohydrate chain, and consists of the kringle-1, one-half of growth factor and one quarter of the kringle- 2 segments. This result also indicates that the kringle1 segment in Fr. 2 is intact. The loss of binding ability of Fr. 1 thus was probably caused by the removal of the peptide segment from kringle-2.

\section{Discussion}

A striking feature of TPA is that its enzyme activity is enhanced 1,000 -fold when the molecule binds to fibrin clots $(7,8)$. The present studies were undertaken to localize the binding site of tPA to fibrin. We first tried to isolate functionally active $A$ and $B$ chains to identify their roles. Interchain disulfide bonds of two-chain forms of serine proteases are usually more susceptible to reducing agent than intrachain disulfide bonds. This was first shown by Robbins et al. (30) in the separation of a heavy and a light chain of plasmin. Later, functionally active polypeptide chains were separated from plasmin (31), urokinase (32), plasma 


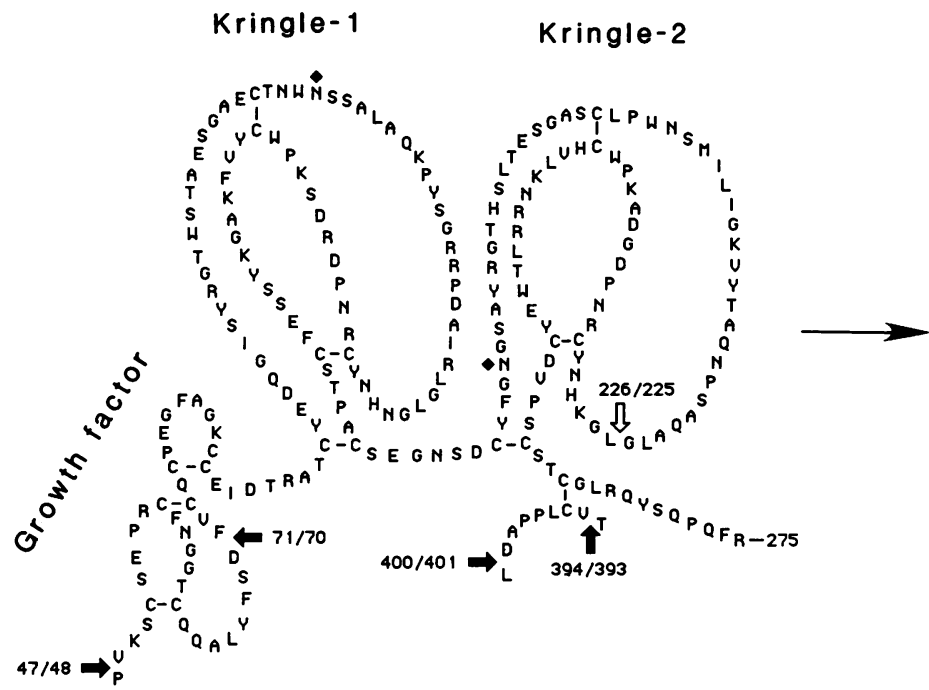

Fr. 1

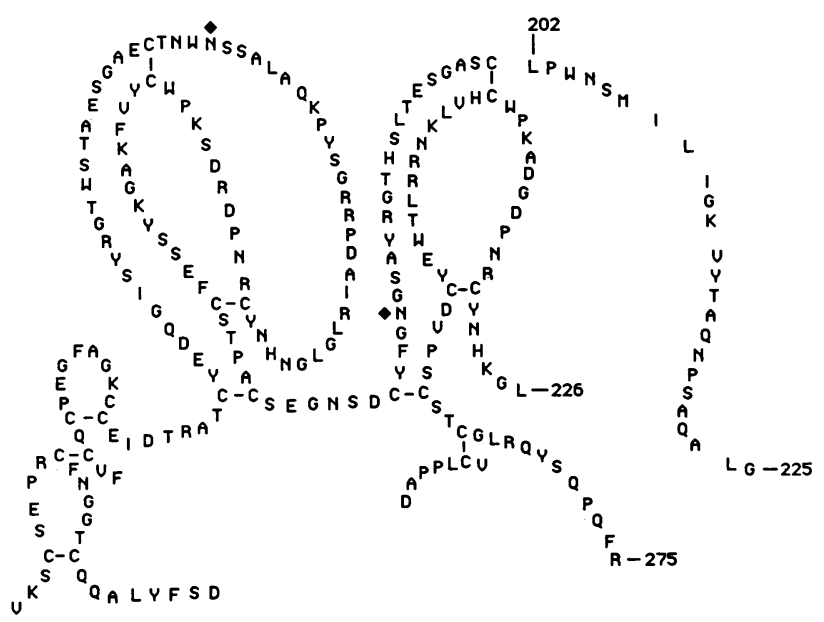

Fr.2

Figure 4. Structure of Fr. 1 (left) and Fr. 2 (right). The sequence was taken from Pennica et al. (19). The single letter codes for amino acid residues were used. The peptide bonds indicated by the solid arrows were cleaved by thermolysin during the conversion of two-chain tPA to Fr. 1 and that shown by the open arrow was cleaved during the conversion of Fr. 1 to Fr. 2. Peptide bond cleavage(s) between Cys 201 and Leu 202 was indicated by the difference in the molecular weights of Fr. 1 and Fr. 2 but not demonstrated by amino acid sequence analysis. The carbohydrate attachment sites are shown by the solid diamonds.

kallikrein (29), and Factor XIa (33). The treatment of two-chain tPA with 5 mM DTT reduced the interchain disulfide bond without affecting the functional activities of both chains. The behavior of the isolated A chain to the lysine-Sepharose column was similar to the intact two-chain tPA molecule; it adsorbed to the column and was retained until the column was eluted with the buffer containing $1 \mathrm{M}$ EACA. The specific amidolytic activity of the separated B chain was $85 \%$ of the intact twochain tPA.

Digestion of the elastase fragment of plasminogen with chymotrypsin produced the intact kringle-1 segment, which was found to be the binding site of plasminogen to lysine or fibrin $(14,15)$. In the case of tPA, thermolysin slowly digested Fr. 1 into Fr. 2 without cleaving a peptide bond in the kringle-1 segment and allowed us to localize the binding site of tPA in the

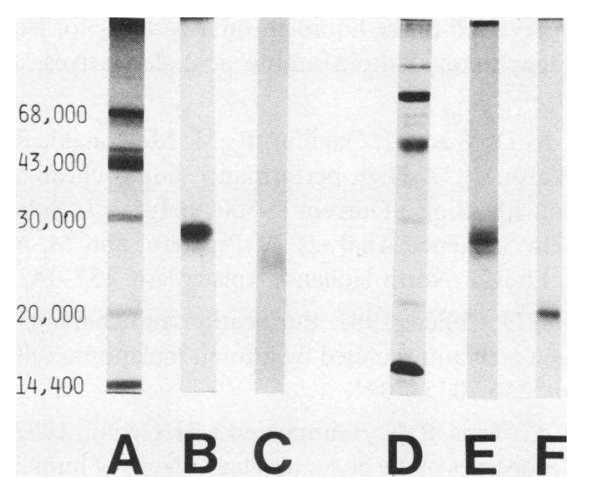

Figure 5. SDS-polyacrylamide slab gel electrophoresis of the fragments, Fr. 1 and Fr. 2. Molecular weight markers $(A$ and $D)$, Fr. 1 $(B$ and $E)$ and Fr. $2(C$ and $F)$. Samples in lanes $A, B$ and $C$ are nonreduced and samples in lanes $D, E$, and $F$ are reduced. kringle-2 segment. This result is consistent with expression experiments in Escherichia coli where partial length tPA lacking in the type I and growth factor segments binds to fibrin-celite (Dr. Donald Foster, personal communication).

The kringle segments are distributed in the amino terminal portions of several serine proteases involved in blood coagulation and fibrinolysis. In addition to plasminogen and tPA, prothrombin (34), urokinase (35), and Factor XII (36) contain the kringle segment in their molecules. Of those proteins, plasminogen and tPA have been known to have binding interaction with fibrin. Recently, single-chain prourokinase was also shown to bind to fibrin, whereas twq-chain urokinase failed to bind (37). In our preliminary experiments, radiolabeled Factor XII and prothrombin did not bind to fibrin (unpublished data). These facts indicate that the presence of the kringle segment is not enough to provide the molecules the binding affinity to fibrin.

The present result showed a possibility that a peptide region between Leu 202 and Gly 225 could be the binding site to fibrin. It is interesting to note that the amino acid sequences of this region are variable among the kringle segments of the different proteins. The binding affinity is possibly determined by the amino acid sequence in this region. This may explain why tPA and plasminogen have affinity to fibrin while the others do not. The extensive reduction of two-chain tPA gave rise to the complete loss of its binding ability. It is thus postulated that the amino acid sequence in the variable region in the correctly folded kringle-2 structure is essential for the binding of tPA to fibrin.

Our experiments found that the binding affinity of tPA to fibrin was much stronger than that of plasminogen. A $50 \%$ inhibition of the binding of tPA to fibrin was observed in the presence of $10 \mathrm{mM}$ EACA (38), while the same degree of inhibition was obtained under the comparable condition for the binding of plasminogen with $0.1-0.13 \mathrm{mM} \operatorname{EACA}(9,11)$. This superior binding affinity of tPA to plasminogen makes it possible 
for tPA to become bound to fibrin clots after it is released from endothelial cells into blood (1-3), where a large excess of plasminogen circulates. The concentrations of plasminogen (39) and tPA $(3,40)$ in blood were reported at $2 \mu \mathrm{M}$ and $0.1 \mathrm{nM}$, respectively. It was reported (41) that $80 \%$ of tPA adsorbed to fibrin at the physiological concentration $(3 \mathrm{mg} / \mathrm{ml})$.

At present, comparative binding parameters for Fr. 1 with the parent molecule, two-chain tPA, are not available. In the case of plasminogen, the binding affinity of kringle 1-3 was found to be substantially weaker than its parent molecule (10). Accordingly, it is probable that the other segments such as type I, growth factor, and kringle- 1 of tPA also contribute to the maximum binding activity of tPA.

\section{Acknowledgments}

The authors thank Dr. Earl W. Davie for his valuable discussion and encouragement throughout this research. Thanks are due to Lee Hendrickson for his help in preparing the manuscript.

This study was supported by National Institutes of Health grants, HL 16919 and GM 15731.

\section{References}

1. Ljungner, H., L. Holmberg, A. Kjeldgaard, I. M. Nilsson, and B. Astedt. 1983. Immunological characterization of plasminogen activators in the human vessel wall. J. Clin. Pathol. 36:1046-1049.

2. Kristensen, P., L.-I. Larssen, L. S. Nielsen, J. Grondahl-Hansen, P. A. Andreasen, and K. Dano. 1984. Human endothelial cells contain one type of plasminogen activator. Fed. Eur. Biochem. Soc. Lett. 168: 33-37.

3. Rijken, D. C., G. Wijngaards, and J. Welbergen. 1980. Relationship between tissue plasminogen activator and the activators in blood and vascular wall. Thromb. Res. 18:815-830.

4. Rijken, D. C., I. Juhan-Vague, F. De Cock, and D. Collen. 1983. Measurement of human tissue-type plasminogen activator by a two-site immunoradiometric assay. J. Lab. Clin. Med. 101:274-284.

5. Aoki, N., Y. Sakata, M. Matsuda, and K. Tateno. 1980. Fibrinolytic states in a patient with congenital deficiency of $\alpha_{2}$-plasmin inhibitor. Blood. 55:483-488.

6. Aoki, N., Y. Sakata, and A. Ichinose. 1983. Fibrin-associated plasminogen activation in $\alpha_{2}$-plasmin inhibitor deficiency. Blood. 62:11181122.

7. Ranby, M. 1982. Studies on the kinetics of plasminogen activation by tissue plasminogen activator. Biochim. Biophys. Acta. 704:461-469.

8. Hoylaerts, M., D. C. Rijken, H. R. Lijnen, and D. Collen. 1982. Kinetics of the activation of plasminogen by human tissue plasminogen activator. J. Biol. Chem. 257:2912-2919.

9. Thorsen, S., P. Glas-Greenwalt, and T. Astrup. 1972. Differences in the binding to fibrin of urokinase and tissue plasminogen activator. Thromb. Diath. Haemorrh. 28:65-74.

10. Thorsen, S. 1975. Differences in the binding to fibrin of native plasminogen and plasminogen modified by proteolytic degradation. Influence of $\omega$-aminocarboxylic acids. Biochim. Biophys. Acta. 393:55-65.

11. Aoki, N., M. Moroi, and K. Tachiya. 1978. Effects of $\alpha_{2}$-plasmin inhibitor on fibrin clot lysis. Its comparison with $\alpha_{2}$-macroglobulin. Thromb. Haemostasis. 39:22-31.

12. Thorsen, S., I. Clemmensen, L. Sottrup-Jensen, and S. Magnusson. 1981. Adsorption to fibrin of native fragments of known primary structure from human plasminogen. Biochim. Biophys. Acta. 668:377-387.

13. Wiman, B., and $P$. Wallen. 1977. The specific interaction between plasminogen and fibrin. A physiological role of the lysine binding site in plasminogen. Thromb. Res. 1:213-222.

14. Lerch, P. G., E. E. Rickli, W. Lergier, and D. Gillessen. 1980.
Localization of individual lysine-binding regions in human plasminogen and investigations on their complex-forming properties. Eur. J. Biochem. 107:7-13.

15. Vali, Z., and L. Patthy, 1984. The fibrin-binding site of human plasminogen. J. Biol. Chem. 259:13690-13694.

16. Allen, R. A., and D. S. Pepper. 1981. Isolation and properties of human vascular plasminogen activator. Thromb. Haemostasis. 45:4350 .

17. Andreasen, P. A., L. S. Nielsen, J. Grondahl-Hansen, L. Skriver, J. Zeuthen, R. W. Stephens, and K. Dano. 1984. Inactive proenzyme to tissue-type plasminogen activator from human melanoma cells, identified after affinity purification with a monoclonal antibody. EMBO J. 3:5156.

18. Wallen, P., N. Bergsdorf, and M. Ranby. 1983. Purification and identification of two structural variants of porcine tissue plasminogen activator by affinity adsorption on fibrin. Biochim. Biophys. Acta. 719: 318-328.

19. Ichinose, A., W. Kisiel, and K. Fujikawa. 1984. Proteolytic activation of tissue plasminogen activator by plasma and tissue enzymes. Fed. Eur. Biochem. Soc. Lett. 175:412-418.

20. Pohl, G., M. Kallstrom, N. Bergsdorf, P. Wallen, and H. Jornvall. 1984. Tissue plasminogen activator: peptide analyses confirm an indirectly derived amino acid sequence, identify the active site serine residue, establish glycosylation sites, and localize variant differences. Biochemistry. 23:3701-3707.

21. Pennica, D., W. E. Holmes, W. J. Kohr, R. N. Harkins, G. A. Vehar, C. A. Ward, W. F. Bennett, E. Yelverton, P. H. Seeburg, H. L. Heyneker, D. V. Goeddel, and D. Collen. 1983. Cloning and expression of human tissue-type plasminogen activator cDNA in E. coli. Nature (Lond.). 301:214-221.

22. Ny, T., F. Elgh, and B. Lund. 1984. The structure of the human tissue-type plasminogen activator gene: correlation of intron and exon structures to functional and structural domains. Proc. Natl. Acad. Sci. USA. 81:5355-5359.

23. Sottrup-Jensen, L., H. Claeys, M. Zajdel, T. E. Petersen, and S. Magnusson. 1978. The primary structure of human plasminogen: isolation of two lysine-binding fragments and one "mini-" plasminogen (MW, 38,000) by elastase-catalyzed-specific limited proteolysis. Prog. Chem. Fibrinolysis Thrombolysis. 3:191-209.

24. Deutsch, D. G., and E. T. Mertz. 1970. Plasminogen: purification from human plasma by affinity chromatography. Science (Wash. DC). 170:1095-1096.

25. Friberger, P., G. Claeson, M. Knos, L. Aurell, S. Arielly, and R. Simonsson. 1979. Activity of plasminogen activators on tripepiide chromogenic substrates. Prog. Chem. Fibrinolysis Thrombolysis. 4:149-153.

26. Glajch, J. L., J. G. Gluckman, J. G. Charikofsky, J. M. Minor, and J. J. Kirkland. 1985. Simultaneous selectivity optimization of mobile and stationary phases in reversed-phase liquid chromatography for isocratic separations of phenylthiohydantoin amino acid derivatives. $J$. Chromatogr. 318:23-39.

27. Ericsson, L. H., R. D. Wade, J. Gagnon, R. M. McDonald, R. Granberg, and K. A. Walsh. 1977. High performance liquid chromatography of PTH-amino acids using a Durrem D-500 analyzer. In Solid Phase Methods in Protein Sequence Analysis. A. Previero, and M.-A. Coletti-Previero, editors. Elsevier/North Holland, Amsterdam. 137-142.

28. Rijken, D. C., and D. Collen. 1981. Purification and characterization of the plasminogen activator secreted by human melanoma cells in culture. J. Biol. Chem. 256:7035-7041.

29. van der Graaf, F., G. Tans, B. N. Bouma, and J. H. Griffin. 1982. Isolation and functional properties of the heavy and light chains of human plasma kallikrein. J. Biol. Chem. 257:14300-14305.

30. Robbins, K. C., L. Summaria, B. Hsieh, and R. J. Shah. 1967. The peptide chains of human plasmin, mechanism of activation of human plasminogen to plasmin. J. Biol. Chem. 242:2333-2342.

31. Rickli, E. E., and W. I. Otavsky. 1975. A new method of isolation 
and some properties of the heavy chain of human plasmin. Eur. $J$. Biochem. 59:441-447.

32. Sumi, H., and K. C. Robbins. 1983. A functionally active heavy chain derived from human high molecular weight urokinase. J. Biol. Chem. 258:8014-8019.

33. van der Graaf, F., J. S. Greengard, B. N. Bouma, D. M. Kerbiriou, and J. H. Griffin. 1983. Isolation and functional characterization of the active light chain of activated human blood coagulation Factor XI. $J$. Biol. Chem. 258:9669-9675.

34. Magnusson, S., T. E. Petersen, L. Sottrup-Jensen, and H. Claeys. 1975. Complete primary structure of prothrombin: isolation, structure and reactivity of ten carboxylated glutamic acid residues and regulation of prothrombin activation by thrombin. In Proteases and Biological Control. E. Reich, D. B. Rifkin, and E. Show, editors. Cold Spring Harbor Laboratory, Cold Spring Harbor, New York. 123-149.

35. Gunzler, W. A., G. J. Steffens, F. Otting, S.-M. A. Kim, E. Frankus, and L. Flohe. 1982. The primary structure of high molecular mass urokinase from human urine: the complete amino acid sequence of the A-chain. Hoppe-Seyler Z. Physiol. Chem. 363:1155-1165.
36. McMullen, B. A., and K. Fujikawa. 1985. Amino acid sequence of the heavy chain of human $\alpha$-Factor XIIa (activated Hageman Factor). J. Biol. Chem. 260:5328-5341.

37. Kasai, S., H. Arimura, M. Nishida, and T. Suyama. 1985. Proteolytic cleavage of single-chain pro-urokinase induces conformational change which follows activation of the zymogen and reduction of its high affinity for fibrin. J. Biol. Chem. 260:12377-12381.

38. Ichinose, A., and K. Fujikawa. Fibrin-binding properties of tissue plasminogen activator. 1985. Thromb. Hemostasis. 54:60 (Abstr.).

39. Rabiner, S. F., Goldfine, I. D., A. Hart, L. Sammaria, and K. C. Robbins. 1969. Radioimmunoassay of human plasminogen and plasmin. J. Lab. Clin. Med. 74:265-273.

40. MacGregor, I. R., and C. V. Prowse. 1983. Tissue plașminogen activator in human plasma measured by radioimmunoassay. Thromb. Res. 31:461-474.

41. Rijken, D. C., M. Hoylaerts, and D. Collen. 1982. Fibrinolytic properties of one-chain and two-chain human extrinsic (tissue-type) plasminogen activator. J. Biol. Chem. 257:2920-2925. 